\section{Functional Status}

Tamara Bushnik

Director of Inter-Hospital Research and Knowledge Translation, Rusk Rehabilitation, New York, NY, USA

\section{Definition}

The ability to perform activities of daily living (ADLs) that are necessary to meet basic needs, fulfill social and community roles, and maintain health and well-being. These activities include, but are not limited to, walking, getting out of bed, cooking, bathing, and dressing. Functional status may be influenced by physical impairment, symptoms, cognitive abilities (or deficits), moods, and health perceptions.

\section{Cross-References}

- Activities of Daily Living (ADLs)

\section{References and Readings}

American Thoracic Society Quality of Life Resource. Functional Status. (2007). http://www.atsqol.org/sec tions/key-concepts/functional-status.html. Accessed 10 Nov 2009. 